\title{
KEANEKARAGAMAN MAKROZOOBENTHOS DI PERAIRAN PANTAI KROKOWOLON DESA WAIARA, KECAMATAN KEWAPANTE KABUPATEN SIKKA, PROVINSI NUSA TENGGARA TIMUR
}

\author{
Maria Imaculata Rume ${ }^{1}$, Sofia Dhengi ${ }^{2}$ \\ ${ }^{1}$ Universitas Nusa Nipa, Maumere, \\ ${ }^{2}$ Universitas Nusa Nipa, Maumere \\ Email: imaculataz@yahoo.co.id
}

Citasi: Rume, I.M, Dhengi, Sofia. 2018. Keanekaragaman Makrozoobenthos Di Perairan Pantai Krokowolon Desa Waiara, Kecamatan Kewapante Kabupaten Sikka, Provinsi Nusatenggara Timur. Mangifera Edu Vol 2 Nomor 2. Hal 89-97

\begin{abstract}
ABSTRAK
Makrozoobentos yang berhabitat di pantai merupakan salah satu kelompok terpenting dalam ekosistem perairan.Secara visual sebaran makrozoobentos yang ada di perairan pantai Krokowolon Desa Waiara Kab.Sikka Nusa Tenggara Timur cukup luas dengan kondisi yang juga cukup beragam.Tujuan penelitian ini adalah memberikan informasi tentag kelimpahan dan keanekaragaman serta potensi di perairan pantai Krokowolon, jenis-jenis makrozoobenthos yang mempunyai nilai ekonomis dan untuk pelestarian makrozoobenthos di perairan pantai Krokowolon. Metode penelitian yang digunakan adalah metode survey dengan observasi langsung yaitu dengan cara mengamati jenis Makrozoobentos yang ditemukan di Perairan Pantai Krokowolon Desa Waiara serta kondisi kualitas perairan sebagai data pendukung. Hasil penelitian jenis makrozoobentos yang ditemukan di perairan pantai krokowolon untuk tiga stasiun penelitian terdiri dari 2 filum yakni filum Mollusca dan filum Echinodermata.Dari filum Mollusca terdapat 2 kelas yakni kelas gastropoda dan bivalvia.Kelas Gastropoda terdiri dari 8 spesies yakni, Pisania striata, Nerita costata, Strombus sp, Viviparus sp, Valvata piscinalis, Rhinocavis vertagus dan Chicoreus palmarosae.Kelas Bivalvia terdiri dari 6 spesies yakni, Trachycardium subrogosum, Chama reflexa, Perglypta purpurea, Anadara sp, Meretrix meretrix, Striarca lactea. Filum Echinodermata ditemukan 4 jenis Echinodermata yaitu jenis Asteria $s p$ (Bintang laut), jenis Ophiotrix fragilis (Bintang mengular), jenis Diadema sp (Bulu babi), jenis Holothuria sp (Teripang). Kisaran suhu untuk stasiun I,II, III berkisar antara $29^{\circ}$ $30^{\circ} \mathrm{C}$ dengan pH yang dinyatakan netral untuk stasiun I - III sedangkan data salinitas pada stasiun I - III berkisar antara 32 - 33\%o dimana kisaran ini masih dalam kondisi optimal untuk pertumbuhan makrozoobentos
\end{abstract}

Kata Kunci : Keanekaragaman, Makrozoobentos, Pantai Krokowolon.

\section{PENDAHULUAN}

Wilayah pesisir merupakan suatu wilayah yang mempunyai potensi sumberdaya alam yang cukup besar. Wilayah ini telah mengalami banyak perubahan fungsi untuk dapat memberikan manfaat dan sumbangan yang besar dalam meningkatkan taraf hidup 
masyarakat melalui peningkatan devisa negara. Pantai merupakan habitat yang dihuni oleh berbagai jenis organisme, baik yang bergerak seperti ikan, udang dan lain sebagainya, dan yang bersifat menetap atau bergerak lambat seperti fauna dasar atau benthos yaitu Mollusca, Polychaeta, Crustacea, Echinodermata.

Makrozoobentos adalah organisme yang hidup di dasar perairan, hidup sesil, merayap, atau menggali lubang.Makrozoobenthos pada umumnya tidak dapat bergerak dengan cepat, ukurannya besar sehingga mudah untuk diidentifikasi (Odum, 1994 dalamSimamora, 2009).Kelimpahan dan keanekaragamannya sangat dipengaruhi oleh toleransi dan sensitivitasnya terhadap perubahan lingkungan.Kisaran toleransi dari makrozoobentos terhadap lingkungan berbeda-beda (Wilhm, 1975 dalam Marsaulina, 1994).

Wilayah Kabupaten Sikka yang terletak di ujung timur Pulau Flores, Provinsi Nusa Tenggara Timur menunjukkan potensi besar bagi pengembangan ekonomi perikanan dan kelautan untuk kesejahteraan masyarakatnya di masa mendatang.Potensi perikanan yang ada di Kabupaten Sikka meliputi perikanan tangkap dan perikanan budidaya.

Perairan Pantai Krokowolon Desa Waiara yang terletak di Kabupaten Sikka memiliki potensi sumberdaya hayati laut yang beragam, salah satunya biota makrozoobentos.Secara visual sebaran makrozoobentos yang ada di perairan pantai Krokowolon Desa Waiara cukup luas dengan kondisi yang juga cukup beragam.Namun data tentang jenis makrozoobenthos itu sendiri belum tersedia, karena belum didukung oleh penelitian-penelitian secara ilmiah sebelumnya.

\section{METODE PENELITIAN}

Penelitian ini dimulai dari studi literatur, survey, observasi, riset, pengumpulan data dan analisa data. pengambilan sampel dilakukan dengan teknik penarikan garis transek, terdiri dari 5 garis transek untuk setiap stasiun dimana garis transek ditarik tegak lurus terhadap garis pantai dengan jarak transek satu ke transek lainnya $10 \mathrm{~m}$, panjang garis disesuaikan dengan luas area penelitian, jumlah kuadran 5 buah dalam satu garis transek, ukuran kuadran 1x1 m, dan jarak antar kuadaran satu dengan lainnya adalah $1 \mathrm{~m}$.

Pengambilan data makrozoobentos dilakukan pada transek kuadran.Organisme makrozoobentos yang ditemukan kemudian diawetkan dengan larutan lugol atau formalin kemudian dimasukkan ke dalam kantong sampel atau botol film untuk diidentifikasi.Identifikasi dilakukan di bawah mikroskop dengan bantuan buku identifikasi. 
Faktor pendukung yang diamati dalam penelitian ini meliputi kecerahan, temperature, salinitas, $\mathrm{pH}$ air, DO.

\section{Analisis Data}

\section{Densitasmakrozoobentos}

Densitas dihitung menggunakan rumus Brower et. al (1990) dalam Sitorus (2008) sebagai berikut:

$$
K=\frac{\mathbf{n i}}{\mathbf{A}}
$$

Keterangan:

$$
\begin{aligned}
& \mathrm{K}=\text { Kepadatan suatu jenis } \\
& \text { ni = Jumlah individu suatu } \\
& \text { jenis A = Luas Area }
\end{aligned}
$$

\section{Frekwensi Kehadiran(FK)}

Krebs, 1985 dalam Sembiring, 2008; Frekwensi Kehadiran (FK) sumberdaya ikan dihitung menggunakan rumus sebagai berikut:

$$
\text { FK }=\frac{\text { Jumlah Plot yang ditempati Suatu Jenis }}{\text { Jumlah Plot yang Ditempati Seluruh Jenis }} \times 100 \%
$$

Keterangan:

$$
\begin{aligned}
& 0-24,9 \% \text { : Sangat } \\
& \text { jarang } 25-59,9 \% \text { : } \\
& \text { Jarang } \\
& 60-74,9 \% \text { : Banyak } \\
& 75-100 \quad \text { : Sangatbanyak }
\end{aligned}
$$

\section{IndeksKeanekaragaman}

Keanekaragaman sumberdaya ikan dihitung dengan menggunakan indeks keanekaragaman dari Shannon dan Wiener (1963) dalam Sitorus (2008) dengan rumus:

$$
\mathrm{H}^{\prime}=-\sum p i \ln p i
$$

Keterangan :

$$
\begin{aligned}
\mathrm{H}^{\prime}= & \text { Indeks keanekaragaman } \\
& \text { Shannon Wienner } \\
\mathrm{Pi}= & \text { ni/N (Perbandingan jumlah individu suatu jenis dengan }
\end{aligned}
$$


seluruh jenis $\ln =$ Logaritma Natural

\section{IndeksDominasi}

Indeks dominasi Simpson (Odum, 1998 dalamSaleky, 2012) menggunakan rumus sebagai berikut:

\section{HASIL DAN PEMBAHASAN}

Hasil pengolahan data pada Tabel1 menjelaskan bahwa nilai indeks keanekaragaman (H') Gastropoda adalah 0,12-0,31, hal ini sesuai dengan klasifikasi indeks keanekaragaman menurut (Krebbs, 1978 dalam Sembiring 2008) $0 \leq \mathrm{H} \leq 2,302$ disimpulkan bahwa pada lokasi penelitian Pantai Krokowolon tergolong Gastropoda dengan keanekaragaman rendah. Nilai indeks kemerataan Gastropoda berdasarkan hasil olahan data yang ditunjukan oleh Tabel1 menunjukan bahwa nilai indeks kemerataan (E)Gastropoda adalah 0,055-0,141 sehingga dapat dinyatakan bahwa nilai indeks kemerataan Gastropoda di perairan Pantai Krokowolon tergolong kemerataan jenis tidak merata. Hal ini sesuai dengan indeks kemerataan Pielau Evennes yang menerangkan jika

$\geq 0,81$ maka penyebaran jenis tidak merata. Sedangkan untuk Nilai indeks dominasi Gastropodasesuai dengan hasil olahan data pada Tabel1adalah $0-0,03$, hal ini sesuai dengan pernyataan Odum(1998) dalam Saleky (2012), jika C mendekati 0 maka tidak ada spesies yang mendominasi, sehingga dapat di simpulkan bahwa tidak ada spesies yang mendominasi di lokasi penelitian Perairan Pantai Krokowolon.

Tabel 1. Jenis-jenis Makrozoobentos di Perairan Pantai Krokowolon Berdasarka HasilIndentifikasi

No. Jenis -

JenisMakrozoobentos

Stasiun

\begin{tabular}{|c|c|c|c|c|}
\hline & & I & II & III \\
\hline \multirow{11}{*}{ A. } & FilumMollusca & & & \\
\hline & Kelas Bivalvia & & & \\
\hline & Trachycardium & $\mathrm{V}$ & $\mathrm{V}$ & $\mathrm{V}$ \\
\hline & Chama reflexa & $\mathrm{V}$ & $\mathrm{V}$ & $\mathrm{V}$ \\
\hline & Perglypta purpurea & $\mathrm{V}$ & $\mathrm{V}$ & $\mathrm{V}$ \\
\hline & Anadara sp & V & V & $\mathrm{V}$ \\
\hline & Meretrix meretrix & $\mathrm{V}$ & $\mathrm{V}$ & $\mathrm{V}$ \\
\hline & Striaca lacteal & - & - & $\mathrm{V}$ \\
\hline & Kelas Gastropoda & & & \\
\hline & Pisania Striata & V & $\mathrm{V}$ & $\mathrm{V}$ \\
\hline & Nerita costata & V & $\mathrm{V}$ & $\mathrm{V}$ \\
\hline
\end{tabular}




\begin{tabular}{llll}
\hline Drupa morum & $\vee$ & $\vee$ & $\vee$ \\
\hline Strombus $s p$ & $\vee$ & $\vee$ & $\vee$ \\
\hline Viviparus $s p$ & $\vee$ & - & - \\
\hline Valvata piscinalis & $\vee$ & $\vee$ & $\vee$ \\
\hline Rhinocavis vertagus & $\vee$ & $\vee$ & $\vee$ \\
\hline Chicoreus palmorosae & $\vee$ & $\vee$ & \\
\hline FilumEchinodermata & & & $\vee$ \\
\hline Kelas Asteroidea & & & $\vee$ \\
\hline Asteria sp & $\vee$ & $\vee$ & \\
\hline Kelas Ophiuroidea & & & \\
\hline Ophiotrix fragilis & $\vee$ & $\vee$ & \\
\hline Kelas Echinoidea & & & \\
\hline Diadema $s p$ & $\vee$ & $\vee$ & \\
\hline Kelas Holothuroidea & & & \\
\hline Holothuria $s p$ & $\vee$ & & \\
\hline
\end{tabular}

Tabel 2. Nilai Kelimpahan (D), Keanekaragaman (H'), Dominansi (C) dan Kemerataan(E) Gastropoda di lokasi Perairan Pantai Krokowolon

\begin{tabular}{clrrrr}
\hline No. & Jenis Gastropoda & D & H' $^{\prime}$ & C & \multicolumn{1}{c}{ E } \\
\hline 1 & Pisania sriata & 0,259 & 0,31 & 0,03 & 0,141 \\
\hline 2 & Nerita costata & 0,178 & 0,26 & 0,02 & 0,12 \\
\hline 3 & Drupa morum & 0,2 & 0,28 & 0,02 & 0,125 \\
\hline 4 & Srombus sp & 0,24 & 0,3 & 0,03 & 0,136 \\
\hline 5 & Viviparous & 0,052 & 0,12 & 0 & 0,055 \\
\hline 6 & Valvata picinalis & 0,2 & 0,28 & 0,02 & 0,12 \\
\hline 7 & Chicereus palmarosae & 0,052 & 0,13 & 0 & 0,055 \\
\hline 8 & Muricidae & 0,096 & 0,18 & 0 & 0,083 \\
\hline 9 & Rhinocavis vertagus & 0,156 & 0,24 & 0,01 & 0,109 \\
\hline & Total & & & &
\end{tabular}

Hasil pengolahan data pada Tabel di atas menjelaskan bahwa nilai indeks keanekaragaman (H') Gastropoda adalah 0,12-0,31, hal ini sesuai dengan klasifikasi indeks keanekaragaman menurut (Krebbs, 1978 dalam Sembiring 2008) $0 \leq \mathrm{H} \leq 2,302$ disimpulkan bahwa pada lokasi penelitian Pantai Krokowolon tergolong Gastropoda dengan keanekaragaman rendah. Nilai indeks kemerataan Gastropoda berdasarkan hasil olahan data yang ditunjukan oleh Tabel di atas menunjukan bahwa nilai indeks kemerataan (E) Gastropoda adalah 0,055 - 0,141 sehingga dapat dinyatakan bahwa nilai indeks kemerataan Gastropoda di perairan Pantai Krokowolon tergolong kemerataan jenis tidak merata. Hal ini sesuai dengan indeks kemerataan Pielau Evennes yang menerangkan jika $\geq 0,81$ maka penyebaran jenis tidak merata. Sedangkan untuk Nilai indeks dominasi Gastropoda sesuai dengan hasil olahan data pada Tabel di atas adalah $0-0,03$, hal ini sesuai dengan pernyataan Simpson Odum(1998) dalam Saleky (2012), jika C mendekati 0 maka https://jurnal.unwir.ac.id/index.php/mangiferaedu|93 
tidak ada spesies yang mendominasi, sehingga dapat di simpulkan bahwa tidak ada spesies yang mendominasi di lokasi penelitian Perairan Pantai Krokowolon.

Tabel 3. Nilai Indeks Keanekaragaman (H'), Dominasi (C) dan Kemerataan Echinodermata di lokasi Perairan Pantai Krokowolon

\begin{tabular}{llrrrr}
\hline No. & Jenis Bivalvia & D & H' $^{\prime}$ & C & \multicolumn{1}{c}{ E } \\
\hline & Trachycardium & & & & \\
1 & Subrugosum & 0,141 & 0,428 & 0,045 & 0,239 \\
\hline 2 & Chama reflexa & 0,089 & 0,183 & 0,018 & 0,102 \\
\hline 3 & Perglypta purpurea & 0,17 & 0,444 & 0,067 & 0,248 \\
\hline 4 & Anadara sp & 0,118 & 0,333 & 0,032 & 0,186 \\
\hline 5 & Meretrix meretrix & 0,104 & 0,453 & 0,025 & 0,253 \\
\hline 6 & Striarca lactea & 0,037 & 0 & 0,003 & 0 \\
\hline & Total & & & & \\
\hline
\end{tabular}

Berdasarkan hasil analisa data pada Tabel di atas maka nilai indeks keanekaragaman $\left(H^{\prime}\right)$ adalah 0,183 - 0,453. Hal ini dapat dilihat pada kriteria persamaan Shannon-Wiener (Krebs, 1989 dalam Yuniarti, 2012) yang menyatakan bahwa ketika nilai $\leq 0 \mathrm{H}^{\prime} \leq 2,302$ maka komunitas dalam kondisi rendah.Berdasarkan perhitungan pada tabel di atas, keanekaragman Bivalvia pada lokasi penelitian tergolong keanekaragaman rendah. Mengacu pada kriteria Indeks Kemerataan (E) Magurran, (1987) dalam Yuniarti (2012) maka dalam penelitian ini Indeks Kemerataan (E) penyebaran Bivalvia pada lokasi penelitian perairan pantai Krokowolon dapat disimpulkan bahwa penyebaran Bivalvia ada yang cukup merata dan ada yang penyebarannya tidak merata merata, hal ini di karenakan nilai Indeks Kemerataan adalah 0,102 - 0,253. Nilai Indeks dominansi Bivalvia di lokasi Penelitian adalah 0,045 hal ini dilihat pada kriteria Indeks dominansi simpson (Magurran, 1987 dalam Yuniarti, 2012) maka disimpulkan bahwa di wilayah penelitian perairan pantai Krokowolon tidak terdapat spesies yang mendominasi. Kelimpahan, Kemerataan serta berlumpur sehingga faktor parameter lingkungan cukup berpengaruh terhadap perkembangan kehidupan Bivalvia, di lokasi penelitian suhu berkisar $29{ }^{\circ} \mathrm{C}$, salinitas 3233\%o sedangkan pH 7. Menurut Suryanto et al. (2002), bahwa kisaran suhu yang optimum untuk mendukung kehidupan Bivalvia berkisar antara 28-32 ${ }^{\circ} \mathrm{C}$,artinya bahwa di Perairan pantai Krokowolon mempunyai suhu yang normal unutk kehidupan Bivalvia, sedangkan menurut Sundari (2002), kisaran salinitas yang dapat mendukung kehidupan Bivalvia pada suatu perairan berkisar antara 30-35\%, artinya bahwa saliniatas dilokasi penelitian tidak berpengaruh terhadap pertumbuhan Bivalvia karena kisaran salinitas 32-33\%o yang sangat 
berpengaruh adalah substrat yang berpasir dan berbatu yang menyebabkan rendahnya Keanekaragaman, Kemerataan dan kelimpahan Bivalvia hal ini dikuatkan dengan pendapat Dahuri (2004) yang menyatakan bahwa jenis Bivalvia merupakan jenis yang banyak ditemukan pada substrat yang berlumpur.

Tabel 4. Nilai Indeks Keanekaragaman (H'), Dominasi (C) dan KemerataanEchinodermata di lokasi Perairan Pantai Krokowolon

\begin{tabular}{clrrrr}
\hline No. & Echinodermata & Kelimpahan & Keanekaragaman & Kemerataan & Dominasi \\
\hline 1 & Asteria $s p$ & 9,252 & 0,35 & 0,253 & 0,237 \\
\hline 2 & Ophiotrix fragilis & 7,193 & 0,368 & 0,265 & 0,143 \\
\hline 3 & Diadema $s p$ & 2,444 & 0,264 & 0,19 & 0,017 \\
\hline 4 & Holothuria $s p$ & 0,104 & 0,028 & 0,021 & 0 \\
\hline & Total & 18,993 & 1,01 & 0,7289 & 0,397 \\
\hline
\end{tabular}

Berdasarkan Tabel di atas menunjukan bahwa analisis data secara keseluruhan dilihat jumlah individu, kelimpahan, keanekaragaman, kemerataan dan dominasi sebagai berikut jenis Asteria sp sebanyak 1249 ekor, jenis Ophiotrix fragilis sebanyak 971 ekor, jenis Diadema sp sebanyak 330 ekor dan jenis Holothuria sp sebanyak 14 ekor. Sedangkan total data secara keseluruhan pada stasiun I, II, III sebanyak 2564 ekor. Total kelimpahan sebanyak `18,993, keanekaragaman sebanyak 1,01040205. Kemerataan sebanyak 0,5013 dan dominasi sebesar 0,3973. Untuk nilai keanekaragaman 1,01040205 Jika dibandingkan dengan nilai kategori maka keanekaragaman berada pada kondisi sedang dimana $1 \leq \mathrm{H}^{\prime} \leq$ 3. Hal ini dipengaruhi oleh adanya faktor aktifitas manusia di daerah zona intertidal pesisir Desa waiara yang selalu menganggu kehidupan Echinodermata tersebut.

Untuk nilai kemerataan berada pada kondisi lebih merata dimana nilai kemerataan 0,7289 berada pada kategori 0,61 - 0,80 pada kondisi jenis lebih merata. Hal ini dipengaruhi oleh kondisi substrat yang berbeda pada stasiun yang berbeda pula.Sedangkan total data secara keseluruhan pada stasiun I, II, III sebanyak 2564 ekor. Total kelimpahan sebanyak `18,993, keanekaragaman sebanyak 1,01040205. Kemerataan sebanyak 0,5013 dan dominasi sebesar 0,3973. Untuk nilai keanekaragaman 1,01040205 Jika dibandingkan dengan nilai kategori maka keanekaragaman berada pada kondisi sedang dimana $1 \leq \mathrm{H}^{\prime} \leq 3$. Hal ini dipengaruhi oleh adanya faktor aktifitas manusia di daerah zona intertidal pesisir Desa waiara yang selalu menganggu kehidupan Echinodermata tersebut.Untuk nilai kemerataan berada pada kondisi lebih merata dimana nilai kemerataan 0,7289 berada pada kategori $0,61-0,80$ pada kondisi 
jenis lebih merata. Hal ini dipengaruhi oleh kondisi substrat yang berbeda pada stasiun yang berbeda pula.

\section{KESIMPULAN}

Kesimpulan yang dapat diperoleh dari hasil penelitian ini yakni diperoleh bahwa jenis makrozoobentos yang ditemukan di perairan pantai krokowolon untuk tiga stasiun penelitian terdiri dari 2 filum yakni filum Mollusca dan filum Echinodermata.Dari filum Mollusca terdapat 2 kelas yakni kelas gastropoda dan bivalvia.Kelas Gastropoda terdiri dari 8 spesies yakni, Pisania striata, Nerita costata, Strombus sp, Viviparus sp, Valvata piscinalis, Rhinocavis vertagus dan Chicoreus palmarosae.Kelas Bivalvia terdiri dari 6 spesies yakni, Trachycardium subrogosum, Chama reflexa, Perglypta purpurea, Anadara sp, Meretrix meretrix, Striarca lactea.penyebaran Bivalvia ada yang cukup merata dan ada yang penyebarannya tidak merata merata, hal ini di karenakan nilai Indeks Kemerataan adalah 0,102 - 0,253.Filum Echinodermata ditemukan 4 jenis Echinodermata yaitu jenis Asteria sp (Bintang laut), jenis Ophiotrix fragilis (Bintang mengular), jenis Diadema sp (Bulu babi), jenis Holothuria sp (Teripang). Tidak ada spesies yang mendominasi pada analisis data ecara keseluruhan.Hal ini diduga diakibatkan oleh aktivitas manusia yang merusak habitat kehidupan Echinodermata.Kisaran suhu untuk stasiun I,II, III berkisar antara 290 - 30 0C. Kisaran suhu yang diukur masih dalam kisaran optimal oleh makrozoobentos dalam pertumbuhannya.Untuk pengukuran $\mathrm{pH}$, dinyatakan netral untuk stasiun I - III.Untuk pengukuran salinitas pada stasiun I - III berkisar antara 32 - 33\%o dimana kisaran ini masih dalam kondisi optimal untuk pertumbuhan makrozoobentos.

\section{DAFTAR PUSTAKA}

Sitorus, Dermawan BR. 2008. Keanekaragaman dan Distribusi Bivalvia Serta Kaitannya Dengan Faktor Fisik-Kimia di Perairan Pantai Labu Kabupaten Deli Serdang. Tesis. USU. Medan.

Sembiring, Herlina. 2008. Keanekaragaman dan Distribusi Udang serta Kaitannya dengan Faktor Fisik Kimia di Perairan Pantai Labu Kabupaten Deli Serdang. Tesis. USU. Medan.

Saleky, Dandi. 2012. Distribusi Temporal Gastropoda Pada Zona Intertidal Berbatu di Pesisir Utara Manokwari Kabupaten Manokwari. Skripsi. UNP. Manokwari.

Dahuri, Rokhmin. 2008. Pengelolaan Sumber Daya Wilayah Pesisir dan Lautan secara Terpadu, Cetakan IV. Jakarta: Pradnya Paramita 
Gunarso W. 1985. Tingkah laku ikan dalam hubungannya dengan alat tangkap, metode dan teknik penangkapan ikan. Bogor: Departemen pemanfaatan sumberdaya perikanan fakultas perikanan dan ilmu kelautan, Institut Pertanian Bogor.

Imbir., Fycki F. Wilhelmina P. \& Johny W. 2015. Pengaruh warna umpan pada hasil tangkapan pancing tonda di perairan Teluk Manado Sulawesi Utara. Jurnal Ilmu dan Teknologi Perikanan Tangkap 2(1): 9-13, Juni 2015.

Kurnia., Sudirman, \& Muhammad Y. 2015. Pengaruh perbedaan ukuran mata pancing terhadap hasil tangkapan pancing ulur di perairan Pulau Sabutung Pangkep. Marine Fisheries. Vol. 6, No. 1, Mei 2015 Hal: 87-95.

Leavastu \& Hela. Fisheries Oceanography. London. Fishing News ( Books) LTD.

Limbong. 2008. Pengaruh suhu permukaan laut terhadap jumlah dan ukuran hasil tangkapan ikan cakalang di Perairan Teluk Palabuhanratu Jawa Barat. Bogor: Departemen Pemanfaatan Sumberdaya Perikanan. Fakultas Perikanan. Institut Pertanian Bogor. 89 hal. 